\title{
As políticas públicas de educação infantil e a utilização de sistemas apostilados no cotidiano de creches e pré-escolas públicas
}

\author{
MARIA LETÍCIA BARROS PEDROSO NASCIMENTO \\ Universidade de São Paulo
}

A crescente institucionalização da infância desemboca numa questão paradoxal, como alerta Qvortrup $(1995 ; 2002)$ : as crianças se beneficiam no convivio com seus pais, mas crianças e pais vivem cada vez mais distantes, em suas vidas cotidianas. $A$ escola como o lugar da criança, na sociedade, tem suas raizes na modernidade, com a invenção da infância moderna, o surgimento da família nuclear e da própria escola,

organização social instituida para a socialização e educação das crianças (Ariés, 1981; James et al., 2002; Sarmento, 2007). Baquero e Narodowski (1994) afirmam que "a infância representa o ponto de partida e o ponto de chegada da pedagogia" (p. 63), argumentando que, a partir do século XVII, foi desenvolvida uma rigorosa categorização da infância e um controle crescente do ambiente infantil, por parte dos adultos - especialistas - a quem foi conferida a autoridade da produção de verdades sobre a educação da criança. Na escola, a relação de aprendizagem estabelecida privilegiou os processos instrucionais, caracterizados pela unilateralidade, e a promoção

de principios morais voltados para a formação de um adulto racional e justo, como convinha à sociedade. A criança tornou-se aluno e foram definidas metas para sua educação e seu desenvolvimento

(Baeuero; Narodowski, 1994; Narodowski, 1999; Dahlberg et al., 2003; Gimeno Sacristán, 2005). 
O conjunto de saberes pedagógicos sobre a infância foi incrementado por outras áreas de conhecimento, como a pediatria e a psicologia, que instituíram padrões de normalidade ao processo de desenvolvimento/aprendizagem, com significativa influência sobre os cuidados familiares e, sobretudo, nas práticas das instituições voltadas às crianças. Em outras palavras, o estatuto de aluno foi complementado por estudos sobre a aprendizagem e sobre a inteligência, que estabeleceram um modelo de desenvolvimento infantil, ressaltando as possibilidades cognitivas das crianças a partir dos sete anos de idade.

Ao longo do tempo, contudo, as crianças de zero a 6 anos, objeto de práticas sociais em ambiente doméstico, foram sendo incorporadas às práticas realizadas em instituições externas à família, dentre as quais as creches, para crianças de famílias das classes populares, e os jardins de infância, no final do século XIX (Kuhlmann Jr., 1998), ou, já no século XX, os parques infantis. A educação da pequena infância era vista como suporte às famílias trabalhadoras, oferecendo às crianças condições de higiene e saúde, além de atividades voltadas ao desenvolvimento normal.

A expansão da educação para os pequenos data dos anos 1970, quando a preocupação com o desenvolvimento cognitivo das crianças foi incorporada pela educação de crianças de 4 a 6 anos, denominada pré-escolar, como medida de prevenção ao futuro insucesso na escola, pela ótica da teoria da educação compensatória (Kramer, 1995). Naquela década, os parques infantis paulistanos tornaram-se Escolas Municipais de Educação Infantil (EMEI), o que ampliou o atendimento aos pré-escolares. Em paralelo, as creches eram consideradas recurso para combater a miséria (Rosemberg, 1989; 1997; Kuhlmann Jr., 2000). Campos e Haddad (1992) constatam que as pesquisas sobre creche e pré-escola, entre 1970 e 1990, tratam do desenvolvimento cognitivo e da estimulação, com vistas a obter comportamentos previstos em escalas de desenvolvimento físico, psicológico e social.

Novas pesquisas sobre a infância, porém, questionavam o modelo de desenvolvimento e de educação infantil, e fizeram emergir o reconhecimento das crianças pequenas como pessoas, propondo novos valores em relação a sua educação. Observe-se que essa concepção se constitui com base no novo paradigma de infância, pautado antes pela criança do que pelo aluno (Sirota, 2001). Segundo Dahlberg,

[...] pesquisas etnográficas com base na sociologia da infância desafiam a concepção de crianças como recipientes passivos de pré-concebidos e inquestionáveis conhecimentos transmitidos por professores que detêm o privilégio da autoridade e uma privilegiada relação com o significado do conhecimento. (2009, p. 230)

$\mathrm{Na}$ nova ótica, crianças pequenas, em creches e pré-escolas, deixam de ser consideradas em seu oficio de aluno (Chamboredon; Prévot, 1986; Sarmento, 2000; 
Sirota, 2001; Gimeno Sacristán, 2005) para tornarem-se visíveis como protagonistas de sua aprendizagem, realizada por meio de interações e brincadeiras, nas quais produzem culturas. ${ }^{1}$ As práticas educativas, então, não se pautam pelo devir, mas pelo conceito de criança "forte, poderosa, competente e, acima de tudo, conectada aos adultos e outras crianças" (Malaguzzi apud Moss e Petrie, 2002, p. 101), como a experiência pedagógica desenvolvida no norte da Itália, cujas condições educativas incorporam a participação das crianças e dos adultos, inclusive dos pais.

A divulgação dessas práticas pedagógicas, desde os anos 1990, aliada ao surgimento dos novos estudos sociais da infância, na mesma década, que reconhecem as crianças como pessoas ativas na "construção e determinação de suas próprias vidas sociais, das vidas daqueles que as cercam e das sociedades nas quais elas vivem" (James, 1997, p. 8), coconstrutoras da sociedade (Qvortrup, 1993; Christensen; Prout, 2005; Corsaro, 1997; Dahlberg et al., 2003), e como atores sociais, proporcionou outra interpretação sobre as relações geracionais, sobre proteção e participação, sobre interações entre grupos de pares infantis e a socialização, a partir do reconhecimento das relações sociais estabelecidas por crianças como interações complexas. A releitura das teorias psicológicas do desenvolvimento, compreendido agora como um processo interativo e cultural (Jobim; Souza, 1996; Corsaro, 1997), e a proposição de uma pedagogia da infância (Rocha, 1999; 2001), pautada pela brincadeira e pela voz das crianças, numa outra organização dos espaços e dos tempos passados em creches e pré-escolas, acrescentou elementos novos à educação infantil.

No Brasil, do ponto de vista da legislação, a Constituição Federal de 1988 tornou-se um marco histórico para a elaboração de políticas para a infância ao determinar creche e pré-escola como direito da criança, dever do Estado e escolha da família (art. 208). O Estatuto da Criança e do Adolescente (ECA), de 1990, referendou o direito à educação desde o nascimento e a Lei de Diretrizes e Bases da Educação Nacional (LDBEN), lei 9.394/96, incorporou a educação infantil ao sistema educacional brasileiro, como primeira etapa da educação básica, e, ao colocar a criança como sujeito de direitos - em vez de objeto de tutela, como nas leis anteriores (Cerisara, 2002) -, provocou uma revisão de concepções e propostas para a educação de crianças de zero a 6 anos de idade (Corrêa, 2002; Campos et al., 1992), e obrigou os sistemas municipais de educação (arts. 11 e 18) a (re)organizarem suas propostas para a educação infantil.

Com o objetivo de orientar as secretarias municipais, o Ministério da Educação (MEC) e o Conselho Nacional de Educação (CNE) publicaram documentos² que ofereciam subsídios para a implementação da educação infantil nos sistemas

1 Mayall (2002) afirma que "é claro que, mesmo sem pesquisa formal, as crianças são atores sociais: elas fazem parte das relações familiares; elas expressam seus desejos, demonstram fortes ligações, ciúmes e prazer, buscam justiça” (apud James, 2009, p. 40-1).

2 Subsidios para Credenciamento e Funcionamento de Instituições de Educação Infantil (Brasil. MEC, 1998a) e Diretrizes Operacionais para a Educação Infantil (Brasil, 2000). 
de ensino. Do ponto de vista do financiamento, ${ }^{3}$ num primeiro momento, durante a vigência da lei do Fundo de Manutenção e Desenvolvimento do Ensino Fundamental e de Valorização do Magistério (FUNDEF) (lei n. 9.424/96; decreto n. 2.264/97), que previa aplicação de recursos no ensino fundamental público, não havia recurso específico para a educação infantil. Em 2007, com a publicação do Fundo de Manutenção e Desenvolvimento da Educação Básica e de Valorização dos Profissionais da Educação (FUNDEB) (lei n. 11.494/07; decreto n. 6.253/07; decreto n. 6.278/07), todavia, os municípios foram amparados para o investimento também na primeira etapa da educação.

Os novos compromissos legais levaram os sistemas públicos de educação, no que diz respeito às creches, a transformar espaços de assistência - ou até mesmo depósitos de crianças - em espaços educacionais, com a presença de professoras e professores formados, no mínimo, em nível médio. Em relação às pré-escolas, os municípios comprometeram-se a proporcionar meios para que professoras e professores avançassem em sua formação e, no que se refere às crianças, de desenvolver projetos contextualizados e significativos. ${ }^{4}$ Cerisara (2002, p. 328) sintetiza esse movimento, afirmando que

A crítica em relação às propostas de trabalho com as crianças pequenas, que se dicotomizavam entre educar e assistir, levou à busca da sua superação em direção a uma proposta menos discriminadora, que viesse atender às especificidades que o trabalho com crianças de 0 a 6 anos exige na atual conjuntura social - de educar e cuidar -, sem que houvesse uma hierarquização do trabalho a ser realizado, seja pela faixa etária ( 0 a 3 anos ou 3 a 6 anos), ou ainda pelo tempo de atendimento na instituição (parcial ou integral), seja pelo nome dado à instituição (creches ou pré-escolas).

Com o objetivo de atender às especificidades do trabalho com crianças de $0 \mathrm{a}$ 6 anos, o MEC publicou, em 1998, o Referencial Curricular Nacional para a Educação Infantil (RCNEI), organizado em três volumes, "Introdução", "Formação pessoal e social" " "Conhecimento do mundo", e, no ano seguinte, o CNE publicou as Diretrizes Curriculares Nacionais para a Educação Infantil (DCNEI) (Resolução CNE/CEB 1/99), mandatórias, pautadas pela concepção de criança como sujeito de direitos e ator social, concepção mantida na recente versão de 2009 (Resolução CNE/CEB 5/09).

Em 2006, a Política Nacional de Educação Infantil, do MEC, reafirmou a concepção de criança como "criadora, capaz de estabelecer múltiplas relações, sujeito de direitos, um ser sócio-histórico, produtor de cultura e nela inserido"

3 As questões e tensões sobre FUNDEF e FUNDEB podem ser encontradas em Arelaro (1999), Guimarães e Pinto (2001), Didonet (2006) e Carreira e Pinto (2007).

4 Ação evidenciada com base na concepção de infância e de educação infantil presente nos documentos de orientação do MEC (1995; 1998a; 1998b; 2006; 2009). 
(Brasil. MEC, 2006, p. 8), e, em 2009, reeditou os Critérios para um atendimento em creches que respeitam os direitos fundamentais das crianças, de 1995, documento que não se pauta por detalhes técnicos, mas pretende afirmar os "compromissos dos políticos, administradores, educadores de cada creche com um atendimento de qualidade, voltado para as necessidades fundamentais das crianças" (Campos; Rosemberg, 2009, p. 7). Assim, o conjunto de documentos de orientação do MEC e as DNCEI tornaram-se as referências para a inclusão da educação infantil nos sistemas municipais de educação.

Em paralelo a esse movimento, escolas particulares começaram a adotar material advindo de Sistemas Privados de Ensino (SPE) em seu cotidiano pedagógico. O material apostilado, elaborado e comercializado por empresas - muitas delas extensões de antigos cursos pré-vestibulares,$-{ }^{5}$ geralmente é criado e desenvolvido para qualquer escola/pré-escola/creche que se disponha a adotá-lo, e acompanhado por cursos e suporte para professores e gestores.

Assim, ao mesmo tempo em que os municípios se municiavam de assessorias, planos de formação de professores, nova organização do sistema educativo próprio e das políticas municipais, em resposta às determinações legais, tomaram contato com os $\mathrm{SPE}^{6}$ para a educação básica, que acenavam com uma suposta garantia de qualidade, assegurada pelo próprio nome da empresa, sua grife. ${ }^{7}$ A eficiência desses materiais parecia comprovada pelo sucesso das escolas (privadas) que os adotavam e, nessa linha, começaram a ser comercializados também nas redes públicas de educação.

Dessa maneira, respondendo ao que a LDBEN 9.394/96 determina nos art. 12 e 14, ou seja, que as redes e as escolas são autônomas para a elaboração de propostas pedagógicas para as comunidades que atendem, respeitadas as Diretrizes Curriculares Nacionais, diferentes prefeituras do estado de São Paulo adotaram os SPE, de acordo com reportagens veiculadas pela imprensa paulistana. ${ }^{8}$ Segundo a imprensa, $25 \%$ dos municípios do estado utilizam os sistemas apostilados.

A adoção dos SPE na educação infantil provocou a pesquisa aqui apresentada, que buscou mapear e verificar quais municípios os utilizam e os motivos presentes nessa escolha, realizada com o apoio da Fundação de Amparo à Pesquisa do Estado de São Paulo (FAPESP).

5 Os primeiros artigos sobre esses cursos datam da década de 1980.

6 Cuja expansão parece ter sido alavancada pelas políticas educacionais de indiscriminada ampliação do número de escolas, consequência da política de cunho neoliberal desenvolvida pelo MEC entre 1995 e 2003.

7 "Ensino com marca registrada e ensino de 'grifes' são expressões utilizadas para esses 'sistemas' que denotariam qualidade e responsabilidade. Tal denotação da marca desperta uma ilusão de que o 'sistema' vendido para escola pública seja o mesmo que é oferecido nas escolas particulares dos vendedores ou nas suas afiliadas" (Tredici, 2007, grifos no original).

8 Folha de S. Paulo, 30/1/2006; 17/4/2007; 03/4/2010; O Estado de S. Paulo, 13/4/2008; 31/8/2008; 27/3/2009. 


\section{A PESQUISA}

Entre os anos 2008 e 2009, a pesquisa foi realizada tendo como objetivos (1) verificar quais redes municipais utilizam os Sistemas Privados de Ensino no estado de São Paulo, por que o fazem e como o fazem, e (2) verificar se os responsáveis técnicos pela educação infantil dos municípios que utilizam os SPE reconhecem esse material como adequado para a educação infantil e como o justificam.

Entre setembro de 2008 e janeiro de 2009 foi enviada carta, por via postal e correio eletrônico, aos $644^{10}$ municípios do estado de São Paulo, convidando-os à participação na pesquisa, por meio de resposta a um questionário, postado em página eletrônica, de fácil acesso, disponível na internet. Uma página derivada desta apresentava os questionários respondidos à pesquisadora e permitia o manuseio e a organização dos dados.

Pretendia-se identificar e caracterizar cada rede, mediante informações sobre $\mathrm{o}$ atendimento prestado em creches e pré-escolas e sobre a equipe de profissionais responsável pelo desenvolvimento do trabalho. Além disso, eram levantadas questões sobre as diretrizes pedagógicas da educação infantil, incluindo Plano Municipal de Educação, e solicitada a indicação dos documentos que sustentavam essas diretrizes, tendo como opções o Referencial Curricular Nacional para a Educação Infantil; os Critérios para um atendimento em creches que respeitam os direitos fundamentais das crianças; as Diretrizes Curriculares Nacionais para a Educação Infantil; a Política Nacional de Educação Infantil; os Sistemas Privados de Ensino; e o campo Outros, seguido da pergunta "Qual?". Pedia-se também que o município indicasse os documentos utilizados para a estruturação do trabalho cotidiano com a educação infantil, com as mesmas alternativas a assinalar.

Foram respondidos 147 questionários, dentre os quais 29 indicavam a adoção de Sistemas Privados de Ensino (SPE). A identificação desses municípios, por região administrativa e população, compõe o Quadro 1, a seguir:

9 "Educação da Infância: o uso de apostilas junto à pequena infância e suas implicações para o reconhecimento da criança como sujeito em desenvolvimento".

10 A capital foi excluída por não utilizar sistemas apostilados, como se verifica no portal da SME-SP (www.http://portalsme.prefeitura.sp.gov.br/default.aspx). Os portais de diferentes municípios foram acessados em busca de informação sobre a adoção de sistemas apostilados, mas os dados efetivos para a pesquisa vieram dos questionários e entrevistas realizadas. 


\section{Quadro 1 - Identificação dos municípios respondentes que utilizam os SPE}

\begin{tabular}{|c|c|c|c|c|}
\hline $\begin{array}{l}\text { Região } \\
\text { administrativa }\end{array}$ & $\begin{array}{l}\text { Menos de } 5 \text { mil } \\
\text { habitantes }\end{array}$ & $\begin{array}{l}\text { De } 5 \text { mil a } 20 \text { mil } \\
\text { habitantes }\end{array}$ & $\begin{array}{l}\text { De } 20 \text { mil a } 100 \\
\text { mil habitantes }\end{array}$ & $\begin{array}{l}\text { Mais de } 100 \text { mil } \\
\text { habitantes }\end{array}$ \\
\hline \multicolumn{5}{|l|}{1} \\
\hline 2 & & & & Araçatuba \\
\hline 3 & Orindiúva & Ariranha & Mirassol & \\
\hline $3 a$ & $\begin{array}{l}\text { Guarani d'Oeste } \\
\text { Indiaporã } \\
\text { Itaju }\end{array}$ & Auriflama & Votuporanga & \\
\hline 4 & $\begin{array}{c}\text { Alvinlândia } \\
\text { Pedrinhas Paulista }\end{array}$ & Ipaussu & & \\
\hline 5 & & Sabino & $\begin{array}{c}\text { Avaré } \\
\text { Lençóis Paulista } \\
\text { Pederneiras }\end{array}$ & \\
\hline 6 & & & Descalvado & \\
\hline 7 & & Serra Azul & $\begin{array}{c}\text { Santa Rosa do } \\
\text { Viterbo } \\
\end{array}$ & \\
\hline 8 & & & Cerquilho & \\
\hline 9 & Jumirim & Charqueada & $\begin{array}{c}\text { Brotas } \\
\text { Capivari }\end{array}$ & \\
\hline 10 & & & Socorro & Indaiatuba \\
\hline \multicolumn{5}{|l|}{11} \\
\hline 12 & & Joanópolis & Pilar do Sul & \\
\hline 13 & & & Juquitiba & \\
\hline 14 & & & & \\
\hline
\end{tabular}

Fonte: IBGE, Portal "Nosso São Paulo".

Nos questionários respondidos, foram indicados 13 SPEs. A maior incidência, entre os 29 municípios respondentes, é do sistema COC/NAME ( 9 municípios), seguido por Positivo (4), Objetivo (3), Anglo (2). Os demais utilizam os sistemas Uno, OPET, Expoente, Pueri Domus, Dinâmico, NetBil, Maxi, Gênese, Passo Livre, que aparecem uma vez cada, como informa o Quadro 2. Dois municípios (Araçatuba e Indaiatuba) indicaram o uso de SPE, mas não o definiram. 
Quadro 2 - Relação SPE - Município

\begin{tabular}{|c|c|c|c|c|c|c|c|c|c|}
\hline COC/NAME & Auriflama & Cerquilho & Descalvado & $\begin{array}{l}\text { Guarani } \\
\text { d'Oeste }\end{array}$ & Indiaporã & Ipaussu & Orindiúva & $\begin{array}{c}\text { Santa Rosa } \\
\text { do Viterbo }\end{array}$ & Serra Azul \\
\hline Positivo & Itaju & Juquitiba & $\begin{array}{l}\text { Lençóis } \\
\text { Paulista }\end{array}$ & $\begin{array}{c}\text { Pedrinhas } \\
\text { Paulista }\end{array}$ & & & & & \\
\hline Objetivo & Charqueada & Joanópolis & Jumirim & & & & & & \\
\hline Anglo & Avaré & Capivari & & & & & & & \\
\hline Uno & Pilar do Sul & & & & & & & & \\
\hline Netbil & Alvinlândia & & & & & & & & \\
\hline Dinâmico & Ariranha & & & & & & & & \\
\hline Maxi & Pederneiras & & & & & & & & \\
\hline Gênese & Sabino & & & & & & & & \\
\hline $\begin{array}{l}\text { Passo } \\
\text { Livre }\end{array}$ & Votuporanga & & & & & & & & \\
\hline OPET & Socorro & & & & & & & & \\
\hline $\begin{array}{l}\text { Pueri } \\
\text { Domus }\end{array}$ & Brotas & & & & & & & & \\
\hline Expoente & Mirassol & & & & & & & & \\
\hline
\end{tabular}

Fonte: Questionários respondidos (2008/2009).

De posse desse material, para atingir o segundo objetivo, pretendia-se entrevistar os dirigentes dos 29 municípios, mas a disponibilidade de agenda dos dirigentes e da pesquisadora acabou por definir o conjunto de entrevistas em 11, realizadas entre maio e dezembro de 2009. Destas, duas foram realizadas por bolsistas de iniciação científica, ${ }^{11}$ cujos projetos derivaram da pesquisa.

Para manter as características das redes públicas de educação infantil respondentes e uma proporção semelhante de SPEs nos municípios que seriam entrevistados, os critérios para escolha de onze municípios ${ }^{12}$ foram: tamanho da população, localização em regiões administrativas, o SPE utilizado, conforme registros que constam no Quadro 3, que se segue:

11 A pesquisa contou com três projetos complementares, realizados como iniciação científica. Um bolsista verificou a situação dos profissionais da educação infantil em um município da Região 13, outro trabalhou com dados da demanda, em município da Região 9, e o terceiro teve como objetivo mapear as empresas responsáveis pelos SPE e verificar o que constitui o conteúdo das apostilas para a educação infantil.

12 A partir deste ponto, os nomes dos municípios serão substituídos por siglas, o que se justifica porque mais importante do que revelar os municípios é compreender a razão pela qual contratam os serviços dos sistemas apostilados para a educação infantil. 
Quadro 3 - Municípios escolhidos - caracterização quanto a população e sistema privado de ensino adotado

\begin{tabular}{|c|c|c|}
\hline Município & $\begin{array}{c}\text { População } \\
\text { (Fonte: IBGE, Contagem da População 2007) }\end{array}$ & SPE \\
\hline M1 & 80.026 & Anglo/Entrelinhas \\
\hline M2 & 20.996 & Pueri Domus \\
\hline M3 & 34.769 & COC/NAME \\
\hline M4 & 29.533 & COC/NAME (UNO) \\
\hline M5 & 173.508 & Em estudo \\
\hline M6 & 3.880 & COC/NAME \\
\hline M7 & 10.671 & Objetivo \\
\hline M8 & 27.777 & Positivo (Nenhum) \\
\hline M9 & 59.366 & Positivo \\
\hline M10 & 9.107 & COC/NAME \\
\hline M11 & 33.080 & OPET \\
\hline
\end{tabular}

Fonte: Questionários respondidos (2008/2009).

A escolha contemplou municípios com densidade populacional diferente, inseridos em nove das 14 regiões do estado e uma proporção aproximada dos SPE: sistema COC/NAME (4 municípios), seguido pelo Positivo (2), sendo que Objetivo, Anglo, Pueri Domus e OPET aparecem uma vez cada.

\section{AS REDES MUNICIPAIS DE EDUCAÇÃO INFANTIL}

Antes de apresentar os dados sobre os sistemas privados de ensino, parece interessante caracterizar as redes públicas visitadas, começando pelo número de crianças matriculadas na educação infantil:

\section{Quadro 4-Caracterização das redes municipais quanto ao atendimento à educação infantil}

\begin{tabular}{|c|c|c|c|c|c|c|c|c|c|}
\hline Município & $\begin{array}{l}\text { Creche } \\
\text { Municipal } \\
\text { Urbana } \\
\text { período } \\
\text { parcial }\end{array}$ & $\begin{array}{l}\text { Creche } \\
\text { Municipal } \\
\text { Urbana } \\
\text { período } \\
\text { integral }\end{array}$ & $\begin{array}{c}\text { Pré-escola } \\
\text { Municipal } \\
\text { Urbana } \\
\text { período } \\
\text { parcial }\end{array}$ & $\begin{array}{c}\text { Pré-escola } \\
\text { Municipal } \\
\text { Urbana } \\
\text { período } \\
\text { integral }\end{array}$ & $\begin{array}{l}\text { Creche } \\
\text { Municipal } \\
\text { Rural } \\
\text { período } \\
\text { parcial }\end{array}$ & $\begin{array}{c}\text { Creche } \\
\text { Municipal } \\
\text { Rural } \\
\text { período } \\
\text { integral }\end{array}$ & $\begin{array}{c}\text { Pré-escola } \\
\text { Municipal } \\
\text { Rural } \\
\text { período } \\
\text { parcial }\end{array}$ & $\begin{array}{c}\text { Pré-escola } \\
\text { Municipal } \\
\text { Rural } \\
\text { período } \\
\text { integral }\end{array}$ & $\begin{array}{l}\text { Total de } \\
\text { crianças }\end{array}$ \\
\hline M1 & 0 & 607 & 1.030 & 429 & 0 & 14 & 33 & 8 & 2.121 \\
\hline M2 & 0 & 99 & 518 & 0 & 0 & 15 & 32 & 0 & 664 \\
\hline M4 & 0 & 192 & 650 & 0 & 0 & 0 & 0 & 0 & 842 \\
\hline M5 & 0 & 2.035 & 3.782 & 0 & 0 & 0 & 0 & 0 & 5.817 \\
\hline M6 & 18 & 23 & 92 & 0 & 0 & 0 & 0 & 0 & 133 \\
\hline M7 & 0 & 168 & 220 & 0 & 0 & 0 & 0 & 0 & 388 \\
\hline M11 & 137 & 256 & 336 & 108 & 33 & 0 & 244 & 0 & 1.114 \\
\hline Totais & 813 & 4.608 & 9.800 & 609 & 33 & 29 & 372 & 8 & 16.272 \\
\hline
\end{tabular}

Fonte: Censo Escolar/2009 - INEP. 
Curiosamente, há discrepância em algumas redes entre os números oficiais, publicados pelo Censo Escolar, e os presentes nas respostas aos questionários, atualizados nas entrevistas. Observe-se que, pelo Censo, não há creche no município M10, mas há uma creche que atende 56 crianças em período integral, como se observa no Quadro 5, a seguir: Quadro 5 - Número de crianças atendidas pelo município, por
categoria: creche/pré-escola

\begin{tabular}{|c|r|r|r|r|}
\hline Município & $\begin{array}{c}\mathbf{N}^{\mathbf{0}} \text { de crianças } \\
\text { em creches } \\
\text { INEP }\end{array}$ & $\begin{array}{c}\mathbf{N}^{\mathbf{0}} \text { de crianças } \\
\text { em creches } \\
\text { Pesquisa }\end{array}$ & $\begin{array}{c}\mathbf{N}^{\mathbf{0}} \text { de crianças } \\
\text { em pré-escolas } \\
\text { INEP }\end{array}$ & $\begin{array}{c}\mathbf{N}^{\mathbf{0}} \text { de crianças } \\
\text { em pré-escolas } \\
\text { Pesquisa }\end{array}$ \\
\hline M1 & 621 & 1.321 & 1.500 & 820 \\
\hline M2 & 114 & 112 & 550 & 485 \\
\hline M3 & 634 & 700 & 805 & 850 \\
\hline M4 & 192 & 300 & 650 & 700 \\
\hline M5 & 2.035 & 2.434 & 3.782 & 3.052 \\
\hline M6 & 23 & 52 & 92 & 146 \\
\hline M7 & 168 & 179 & 220 & 211 \\
\hline M8 & 1.092 & 50 & 524 & 1.302 \\
\hline M9 & 0 & 1.020 & 1.710 & 2.156 \\
\hline M10 & 426 & 220 & 268 & 240 \\
\hline M11 & 5.465 & 6.444 & 10.789 & 10.956 \\
\hline Totais & & & & 994 \\
\hline
\end{tabular}

Fonte: Censo Escolar/2009 - INEP/Questionários.

Chama a atenção a inversão presente nos números de M1, mas, de acordo com a entrevista realizada, "esses 1.321 estão de zero a cinco, das creches [...] dentro das creches, dentro das 13 que funcionam, nós temos pré-escola", o que permite compreender que crianças de até 5 anos são atendidas em creches e em pré-escolas, o que parece justificar a discrepância.

Destaque-se que, nas redes de M8, M9 e M11, há um decréscimo de matrículas na creche, o que parece indicar que crianças de 3 anos estivessem sendo encaminhadas para a pré-escola, à semelhança do que aconteceu na rede pública paulistana em 2009/2010. ${ }^{13}$ De qualquer modo, os números obtidos na pesquisa revelam um total de 1.144 crianças a mais do que no Censo Escolar.

13 Conforme Portal da SME/SP (http://portalsme.prefeitura.sp.gov.br/anonimo/ demanda.aspx). Em 2011, as crianças de 3 anos voltaram para as creches. 
Ainda assim, a demanda supera a oferta, como revelam as entrevistas. ${ }^{14} \mathrm{O}$ caso mais evidente de déficit de atendimento é o de M1, onde, na avaliação do Secretário,

Não temos espaço físico suficiente. Inclusive, nós estamos sendo cobrados pela promotoria pública em função disso. [...] a demanda é muito maior do que a possibilidade de adequar o local. [...] uma multa diária. É uma ação judicial já transitada e julgada, em função da gente não conseguir atender [...] recebemos da promotoria um ultimato, vamos dizer assim, para que a gente atendesse até o final do ano, pelo menos, 653 crianças.

M7, M9, M10 e M11 apresentam problemas de demanda e de adequação de vagas/espaço físico para seu atendimento. A manutenção de período integral para creche e pré-escola aparece em M6, M9 e M10, enquanto M11 tem uma unidade de pré-escola no período integral. A maioria dos municípios está investindo na construção de novas unidades.

As redes indicaram que tinha havido - ou estava previsto - concurso público para contratação de professores. Observa-se, contudo, que existe significativa diferença entre pré-escolas, que contam com professores para todos os grupos de crianças, e creches, onde há diferentes profissionais atuando com as crianças - pajens, em M1; monitores em M4, M9 e M10; auxiliares de creche em M2; auxiliares de desenvolvimento infantil em M7, onde também trabalham recreacionistas, nem todas com formação em, no mínimo, nível médio, conforme a LDB 9.394/96; e professores, em M3, M6 e M11. O trabalho com a formação continuada, ministrado pelas secretarias ou pelos SPE, não abrange a totalidade dos profissionais, mas somente os professores em qualquer uma das redes.

A parceria com as famílias, prevista em lei, não era tema das entrevistas, mas apareceu em algumas delas, ou como pressão por qualidade, na exigência de manutenção do sistema apostilado, ou como assistência, dada uma suposta precariedade das famílias em cuidar de suas crianças, conforme se evidencia na entrevista de M7. Naquele município, a creche é reconhecida como espaço de assistência. Em M10, a referência às famílias é a ausência motivada pelo trabalho:

Senti lá, esse ano, a necessidade de o ano que vem estar trabalhando bastante com a família. [...] a gente tinha pensado em promover algumas atividades com a família, levar a família para a creche mesmo [...] O problema maior nosso é que todos trabalham.

14 A partir deste ponto são excluídos M5 e M8, visto que os dois municípios apontaram a utilização dos sistemas apostilados nas respostas ao questionário, mas as entrevistas revelaram que, de fato, não o fazem, o primeiro porque não encontrou um sistema adequado ainda e o segundo município, porque deixou de utilizá-lo. Assim, as considerações vão se referir a nove municípios. 
A questão principal da parceria educação infantil-família, ou seja, "o debate público sobre formas de socialização infantil não parental e a responsabilidade compartilhada entre família e estado quanto à educação da criança pequena no seu sentido mais amplo" (Haddad, 2003, p. 43) não se revela nas entrevistas.

Ficou evidenciado certo desconhecimento da educação infantil como primeira etapa da educação básica em M7, talvez porque as dirigentes tenham sido professoras da rede estadual por muitos anos, tendo trabalhado somente com o ensino fundamental, o que fez com que, na entrevista, fosse necessário, mais de uma vez, trazer os temas tratados para a educação infantil. Em M10, as entrelinhas, a forma lacônica das respostas, a referência ao recente papel de gestor/administrador fez entrever que, de fato, não há projeto pedagógico para a educação infantil, mas a expectativa de que, com a construção da unidade do ProInfância,${ }^{15}$ este seja elaborado.

Do ponto de vista da lei, os municípios têm um Plano Municipal de Educação, conforme os depoimentos coletados. Contudo, o documento não necessariamente foi elaborado pelo município, mas por empresas contratadas com essa finalidade, como em M6, por exemplo, onde o acesso ao documento foi permitido à pesquisadora.

As diretrizes pedagógicas e o trabalho cotidiano das redes que participaram das entrevistas têm como base o Referencial Curricular Nacional para a Educação Infantil, ${ }^{16}$ documento que apresenta objetivos, conteúdos e orientações didáticas para cada eixo de trabalho. Se for considerado que essa organização implica o "perigo de que venha a ser utilizado de modo instrumental pelos professores" (Cerisara, 1999, p. 33), sua utilização acarretaria o desenvolvimento de um trabalho à semelhança daquele realizado no ensino fundamental, ou seja, considerando a criança como aluno, questão já apresentada na introdução do texto. Segundo a equipe de M11, "no Referencial, ele vem especificando bem o que tem que trabalhar na criança daquela faixa etária, e o material põe aquilo em prática”, ou seja, o conteúdo das apostilas seria complementar ao RCNEI, questão que será discutida mais adiante.

15 Programa Nacional de Reestruturação e Aquisição de Equipamentos para a Rede Escolar Pública de Educação Infantil (ProInfância), visando à construção de creches e escolas de educação infantil e a aquisição de equipamentos para a rede física escolar dessa etapa. Instituído pela Resolução n. 6, de 24 de abril de 2007.

16 Uma severa crítica ao documento foi realizada quando a versão preliminar do documento foi encaminhada a 700 profissionais ligados à área da educação infantil, em 1998, e o GT07 - Educação da Criança de 0 a 6 anos - da ANPEd, na Reunião Anual daquele ano, optou por debater a questão com base em trabalho encomendado: "A produção acadêmica na área da educação infantil a partir da análise de pareceres sobre o Referencial Curricular Nacional da Educação Infantil: Primeiras aproximações”, elaborado por Ana Beatriz Cerisara. A própria ANPEd publicou parecer institucional, em 1998, na Revista Brasileira da Educação (n. 7, p. 89-96). A discussão foi retomada na publicação Educação Infantil pós-LDB: rumos e desafios, organizada por Faria e Palhares (1999). 


\section{A UTILIZAÇÃO DOS SISTEMAS APOSTILADOS NA EDUCAÇÃO INFANTIL}

O primeiro dado que se destaca nas entrevistas é que a adoção dos sistemas apostilados data dos anos 2000: M3 e M4 contrataram em 2000; M2 e M11, em 2004; M7, em 2005; M9 e M1, em 2006; M6 e M10, em 2008. Isso leva a pensar que, se a década de 1990 foi a da grande conquista da educação infantil como nível da educação, a década seguinte foi a da comercialização dos SPE como proposta pedagógica para creches e pré-escolas. Essa evidência parece significar que as empresas não perderam tempo em elaborar e distribuir seu material. As apostilas predominam nas pré-escolas, e, de acordo com as informações obtidas, são utilizadas a partir dos 3 anos de idade.

Por que as redes públicas utilizam os sistemas apostilados na educação infantil? É possível elencar entre os motivos o fato de as professoras ${ }^{17}$ não estarem preparadas, faltar-lhes experiência, faltar-lhes disposição para preparar/trabalhar com atividades adequadas à educação infantil (M1, M6, M7 e M9). Nesse sentido, além de fornecer o material, os sistemas oferecem orientação/acompanhamento da utilização do material, esclarecendo dúvidas, sugerindo como desenvolver as atividades propostas e até avaliando as crianças, como em M6.

Outro motivo parece ser o fato de que o material apostilado corresponde ao currículo proposto pelo município, que, por sua vez, é retirado do RCNEI (M2, M4 e M9), ao qual parece ser possível acrescentar que o sistema oferece continuidade/ padronização desse conteúdo (M1, M2, M3, M7 e M11). Sobre a questão, diz a dirigente de M1 que:

Temos muitos professores contratados [...] todo ano tem que existir esse processo seletivo. Então nós não sabemos ainda como o professor está preparado. $\mathrm{E}$, através do processo, nós temos que colocá-los dentro da rede. Então a partir do momento que você direciona, você está garantindo, pelo menos, o mínimo. Através do acompanhamento durante o ano. [...] E aí nós padronizamos, não é? [...] A vantagem que a gente enxerga é essa história do aluno de repente estar estudando aqui e ele vai para uma outra escola e ele tem a continuidade. [...]Então a questão da apostila, um lado positivo seria essa padronização.

Ao mesmo tempo, o SPE possibilita a flexibilização do conteúdo - e da forma, como em M11 -, de acordo com as necessidades do município (M3, M6, M9), garantindo seu mínimo.

As redes apresentam ainda outro motivo, o papel político da utilização de um sistema conhecido, que torna a escola pública supostamente semelhante à

17 A partir daqui será utilizada a forma feminina da palavra, visto que não existem professores na educação infantil nos municípios pesquisados. 
privada (M4, M9), além de satisfazer o acompanhamento da família em relação ao desempenho das crianças (M1, M4, M6, M7, M9). Em M4, a dirigente, em nova gestão administrativa, rompeu com o uso do SPE, mas a pressão das famílias obrigou a Secretaria de Educação a retomar a utilização de sistema apostilado, substituindo-o por outro, depois de seis meses. A força política, talvez mais que a pedagógica, aparece também no depoimento da secretária de Educação de M7, quando se refere aos bons índices do município no IDEB: "eu tenho medo de tirar [as apostilas] e o IDEB cair".

Comprometidas com os sistemas apostilados, as redes buscam garantir certa identidade pedagógica, o que se depreende das intervenções feitas na organização/ composição do material e da complementação oferecida: M1 sustenta que há um plano para chegar à atividade da apostila, que inclui o brincar; M2 afirma que tem autonomia para o trabalho com conteúdos; M3 aponta o projeto ambiental desenvolvido em paralelo; M6 propõe projeto de dramatização; M9 assegura que há desenvolvimento de situações pedagógicas pela professora, finalizadas com a utilização da apostila; M10 destaca que as professoras não se prendem ao material apostilado, desenvolvendo pequenos projetos paralelos. O único município que ensaia uma crítica aos sistemas é M1, ao indicar que a utilização das apostilas propicia um trabalho mecânico, que não dá margem para a criatividade. Ainda assim, mantém os SPE.

As entrevistas desvelam ainda a concepção de educação infantil presente nas redes públicas, de maneira geral, que é aquela que tem como objetivo a preparação para o ensino fundamental, seja reconhecendo essa preparação como objetivo, como em M10, por meio do trabalho com a psicomotricidade, ou como um suporte para a elaboração de conceitos, competências e habilidades, como em M4, ou, ainda, desenvolvendo a coordenação motora e a formação de hábitos, como em M7. Os conteúdos são providos pelo material apostilado.

O brincar, contudo, está presente nos depoimentos: M1 incorpora o brincar, o movimento, o pensamento simbólico nas atividades cotidianas; M6 reforça que as crianças menores têm oportunidade de vivenciar o lúdico e a brincadeira; ${ }^{18} \mathrm{M} 10$ propõe um brincar pedagógico por meio de "pequenos projetos [...] onde fazia a integração com o lúdico. Por exemplo, círculos no chão, para trabalhar formas geométricas, o próprio parque, blocos lógicos". A brincadeira e a interação como eixos das práticas pedagógicas, conforme as atuais DNCEI (art. 9०), ou como base para a compreensão das relações sociais, de acordo com os estudos sociais sobre a criança, parecem não ter lugar no cotidiano da educação infantil.

18 Enquanto as maiores são avaliadas pelos técnicos do sistema, que "tomam leitura, de acordo com o nível da sala, conhecimento de letra, identificação de símbolos”. 
Verifica-se ainda que creche e pré-escola têm papéis diferentes, seja pelo nível de escolarização das professoras e consequente denominação profissional, por sua participação nos projetos de formação continuada, ou pela baixa inclusão dos pequeninos nos sistemas apostilados.

\section{POLÍTICAS PÚBLICAS E SISTEMAS APOSTILADOS}

Cabe refletir sobre os motivos para a adoção dos SPE, apresentados no segmento anterior. Sobre o primeiro motivo, o despreparo do corpo docente, há diferentes caminhos a seguir. Um deles seria a crítica aos cursos de formação de professores, mas essa discussão não caberia neste artigo, pela própria extensão. É responsabilidade das redes, entretanto, providenciar a formação continuada, qualificando seu corpo docente. $\mathrm{O}$ acompanhamento oferecido pelos SPE, ainda que possa ter formato semelhante à formação continuada, é, geralmente, treinamento para o uso do material ou avaliação do desenvolvimento das atividades, ou seja, o foco são as apostilas e não as professoras e professores.

Dessa forma, os sistemas apostilados praticam um empobrecimento da função docente, restringindo sua ação às orientações prescritivas presentes nas apostilas, ou seja, dispensa professores e professoras da "responsabilidade de escolher, e do incômodo de experimentar algo diferente do que normalmente se faz" (Fortunati, 2009, p. 36). A responsabilidade da formação continuada é, assim, deslocada para o âmbito do privado, muitas vezes, sem qualquer supervisão das redes, visto que o investimento nos SPE abrange também essa modalidade.

Nessa linha, talvez a semelhança com o RCNEI, alegada pelos dirigentes entrevistados, segundo motivo apontado para a adoção das apostilas, dê segurança às redes públicas. No que se refere à semelhança apontada, no RCNEI

[...] volumes pretendem contribuir para o planejamento, desenvolvimento e avaliação de práticas educativas que considerem a pluralidade e diversidade étnica, religiosa, de gênero, social e cultural das crianças brasileiras, favorecendo a construção de propostas educativas que respondam às demandas das crianças e seus familiares nas diferentes regiões do país. (Brasil. MEC, 1998)

Nas apostilas examinadas, ${ }^{19}$ os conteúdos estão organizados em "linguagem oral e escrita", "movimento", "natureza e sociedade", como o documento do MEC. Entretanto, apresentam exercícios de rabiscação, perfuração, dobragem, recorte e colagem e labirintos, ou seja, atividades de psicomotricidade, além de exercícios com letras do alfabeto ou com numerais, cores, figuras geométricas, tamanhos e

19 Cf. nota de rodapé 10. 
posições, por exemplo, repetindo os modelos preparatórios das décadas de 1970 e 1980. As atividades presentes nas apostilas estão distantes de

[...] um currículo sustentado nas relações, nas interações e em práticas educativas intencionalmente voltadas para as experiências concretas da vida cotidiana, para a aprendizagem da cultura, pelo convívio no espaço da vida coletiva e para a produção de narrativas, individuais e coletivas, através de diferentes linguagens. (Brasil. MEC, 2009)

Há uma evidente discrepância nas concepções de infância e de educação infantil entre as orientações do MEC e os conteúdos das apostilas, ainda que não reconhecida pelos dirigentes nas entrevistas realizadas, o que parece indicar a ausência de uma avaliação pedagógica mais detalhada do material por ocasião da contratação do SPE.

Outro ponto destacado pelos municípios, a padronização dos conteúdos - e sua flexibilização nas práticas cotidianas -, remete à manutenção da visão de criança como aluno e, de novo, ao predomínio da importância do material, nesse caso sobre as crianças. Se as apostilas garantem as atividades promovidas e facilitam a continuidade, numa eventual transferência de crianças de uma creche/pré-escola para outra, elas empobrecem a articulação das

$[\ldots]$ experiências e $[\mathrm{d}]$ os saberes das crianças com os conhecimentos que fazem parte do patrimônio cultural, artístico, científico e tecnológico. Tais práticas são efetivadas por meio de relações sociais que as crianças desde bem pequenas estabelecem com os professores e as outras crianças, e afetam a construção de suas identidades. (Brasil, 2009b, p. 6)

Essa definição de currículo, presente na recente publicação de versão atualizada das DCNEI (Parecer CNE/CB 20/09), prevê a participação das crianças - e dos professores e professoras - nas experiências pedagógicas e uma flexibilização de propostas, que se dá mais pela pluralidade e pela diversidade do que pela alternativa de inserção de atividades mais livres ou lúdicas aos conteúdos das apostilas, apontadas pelos dirigentes. Segundo Fortunati (2009, p. 38),

[...] assumir uma imagem forte, rica e potencial da infância necessita uma correspondente transformação do papel do adulto em uma direção em que sua ação se desenvolve muito mais sobre a organização de contextos estruturantes que sobre a proposta de estímulos diretos no fazer das crianças.

Em relação ao quarto motivo, que traz em si o peso político da grife parceira e a qualidade do material, atestada pelo sucesso obtido por escolas privadas, parece interessante apontar que o material apostilado vendido às prefeituras talvez não seja o mesmo, visto que algumas das empresas desenvolveram uma linha específica 
para atendimento às redes públicas. $\mathrm{O}$ portal do $\mathrm{COC},{ }^{20}$ por exemplo, apresenta o COC/NAME (Núcleo de Apoio à Municipalização do Ensino), específico para o segmento público, provavelmente diferente daquele oferecido às escolas privadas. O site informa que os resultados no IDEB ficam acima da média nacional para os municípios parceiros, o que parece responder à necessidade das redes de números positivos no ensino fundamental. A educação infantil, aqui, volta a ser concebida como devir, como preparação para o ensino escolar. Entretanto,

[...] enquanto a escola tem como sujeito o aluno, e como o objeto fundamental o ensino nas diferentes áreas, através da aula; a creche e a pré-escola têm como objeto as relaçôes educativas travadas num espaço de convívio coletivo que tem como sujeito a criança de 0 a 6 anos de idade (ou até o momento em que entra na escola). (Rocha, 2001, p. 31, grifos do autor)

Os objetivos da pesquisa - verificar quais redes municipais utilizam os Sistemas Privados de Ensino no estado de São Paulo, por que o fazem e como o fazem, e verificar se os responsáveis técnicos pela educação infantil dos municípios que utilizam os SPE reconhecem esse material como adequado para a educação infantil e como o justificam - foram atingidos. Os procedimentos utilizados revelaram a parceria de 29 municípios, dentre 147, com os SPE, dos quais nove foram objeto de análise. Os dados obtidos revelam que há uma forte cultura ${ }^{21}$ pré-escolar no trabalho com a educação infantil, no sentido preparatório, com ênfase nas habilidades requeridas para o desempenho escolar posterior, o que parece limitar a construção de uma identidade da educação infantil nas redes municipais de educação, com base nas orientações do MEC e das determinações do CNE. A adoção dos sistemas privados de ensino restringe a construção de um projeto pedagógico ${ }^{22}$ para essa etapa da educação básica.

20 Acesso por meio do site: $\langle$ http://www.coc.com.br/>.

21 Denominada "tradição pré-primária" no relatório da OECD, Starting Strong II, de 2006, que contém pesquisa sobre educação infantil realizada em vinte países.

22 "Art. 4o As propostas pedagógicas da Educação Infantil deverão considerar que a criança, centro do planejamento curricular, é sujeito histórico e de direitos que, nas interações, relações e práticas cotidianas que vivencia, constrói sua identidade pessoal e coletiva, brinca, imagina, fantasia, deseja, aprende, observa, experimenta, narra, questiona e constrói sentidos sobre a natureza e a sociedade, produzindo cultura." (Brasil, 2009b). 


\section{REFERÊNCIAS}

ArELARo, Lisete R. G. Financiamento e qualidade da educação brasileira: algumas reflexões sobre o documento "Balanço do primeiro ano do FUNDEF - Relatório MEC". In: . Financiamento da educação básica. Campinas: Autores Associados; Goiânia: Ed. da UFG, 1999.

ARIÉs, Philippe. História social da criança e da família. Tradução Dora Flaksman. 2. ed. Rio de Janeiro: Zahar, 1981.

Baguero, Ricardo; Narodowski, Mariano. ¿Existe la infancia? Revista del Instituto de Investigaciones en Ciencias de la Educación, Buenos Aires: Facultad de Filosofía e Letras UBA, v. 3, n. 6, p. 61-66, 1994.

Brasil. Lei 9.394, de 20 de dezembro de 1996. Lei de Diretrizes e Bases da Educação Nacional. Brasília, DF: Ministério da Educação, 1996.

. Lei n. 9.424, de 24 de dezembro de 1996. Fundo de Manutenção e Desenvolvimento do Ensino Fundamental e de Valorização do Magistério - FUNDEF. Brasília, 1996.

. Parecer CEB 022/98; Resolução CEB 1/1999. Diretrizes Curriculares Nacionais para a Educação Infantil. Brasília, DF: Conselho Nacional de Educação. Câmara da Educação Básica, 1999.

. Parecer CNE/CEB 4/2000, de 16 de fevereiro de 2000. Diretrizes Operacionais para a Educação Infantil. Brasília, DF: Conselho Nacional de Educação. Câmara da Educação Básica, 2000.

. Lei 10.172, de 9 de janeiro de 2001. Plano Nacional de Educação. Diário Oficial da União, Brasília, 10 de janeiro de 2001, Seção I, p. 3-5.

. Lei n. 11.494, de 24 de junho de 2007. Fundo de Manutenção e Desenvolvimento da Educação Básica e de Valorização dos Profissionais da Educação - FUNDEB. Brasília, 2007.

Instituto Brasileiro de Geografia e Estatística. Contagem da população. 2007. Disponível em: <http://www.ibge.gov.br/home/estatistica/populacao/contagem2007/ default.shtm>. Acesso em: dez. 2008.

. Instituto Nacional de Estudos e Pesquisas Educacionais Anísio Teixeira. Censo Escolar da Educação Básica. 2009a. Disponível em: <http://www.inep.gov.br/ basica/censo/censo.asp>. Acesso em: mar. 2010.

. Parecer CNE/CEB 020/2009. Resolução CNE/CEB n. 5/2009. Diretrizes Curriculares Nacionais para a Educação Infantil. Brasília, DF: Conselho Nacional de Educação; Câmara da Educação Básica, 2009b.

Brasil. MEC- Ministério da Educação. Política Nacional de Educação Infantil. Brasília: MEC/SEF/DPE/COEDI, 1994. 
- Critérios para um atendimento em creches que respeite os direitos fundamentais das crianças. Brasília: MEC/SEF/DPE/COEDI, 1995.

- Subsidios para credenciamento e funcionamento de instituições de educação infantil. Brasília: MEC/SEF/DPE/COEDI, 1998a. 2 v.

. Referencial Curricular Nacional para a Educação Infantil. Brasília: MEC/ SEF/DPE/COEDI, 1998b. 3 v.

- Politica Nacional de Educação Infantil: pelo direito das crianças de zero a seis anos à educação. Brasília: MEC/SEF/DPE/COEDI, 2006.

.Projeto de Cooperação Técnica MEC e UFRGS para Construção de Orientações Curriculares para a Educação Infantil. Práticas Cotidianas na Educação Infantil: Bases para a Reflexão sobre as Orientações Curriculares. Brasília: MEC/UFRGS, 2009.

CAmpos, Maria M.; HADdAD, L. Educação infantil: crescendo e aparecendo. Cadernos de Pesquisa, São Paulo: Fundação Carlos Chagas; São Paulo: Cortez Editora, n. 80, p. 11-20, fev. 1992.

Campos, Maria M.; Rosemberg, Fúlvia; Ferreira, Isabel M. Creches e pré-escolas no Brasil. São Paulo: Cortez, 1992.

Campos, Maria M.; Rosemberg, Fúlvia. Critérios para um atendimento em creches que respeitam os direitos fundamentais das crianças. 6. ed. Brasília: MEC, SEB, 2009.

Carreira, Denise; Pinto, Jose Marcelino R. Custo aluno-qualidade inicial: rumo à educação pública de qualidade no Brasil. São Paulo: Global, 2007.

Cerisara, Ana B. A produção acadêmica na área da educação infantil a partir da análise de pareceres sobre o referencial curricular nacional da educação infantil: primeiras aproximações. In: Faria, Ana Lúcia G. de; PAlHares, Marina. Educação infantil pós-LDB: rumos e desafios. Campinas: Autores Associados; São Carlos: Ed. da UFSCAR; Florianópolis: Ed. da UFSC, 1999.

. O Referencial Curricular Nacional para a Educação Infantil no contexto das reformas. Educação e Sociedade, v. 23, n. 80, p. 326-345, set. 2002.

Chamboredon, Jean C.; Prevót, Jean. O “ofício da criança”. Definição social da primeira infância e funções diferenciadas da escola maternal. Cadernos de Pesquisa, São Paulo: Fundação Carlos Chagas; São Paulo: Cortez Editora, n. 59, p. 32-56, nov. 1986.

Christensen, Pia; Prout, Alan. Anthropological and sociological perspectives on the study of children. In: GREEnE, Sheila; HogAn, Diane (Ed.). Researching children's experience. Approaches and Methods. London: Sage, 2005.

CorrêA, Bianca C. A educação infantil. In: OliveIra, Romualdo P.; Adrião, Theresa. (Org.). Organização do ensino no Brasil. São Paulo: Xamã, 2002.

Corsaro, William A. The sociology of childhood. Thousand Oaks, California: Pine Forge Press, 1997. 
DAhlberg, Gunilla. Policies in Early Childhood Education and Care. In: QvorTruP, Jens; Corsaro, William A.; Honig, Michael-Sebastian The Palgrave Handbook of Childhood Studies. London: Palgrave, 2009.

Dahlberg, Gunilla; Moss, Peter; Pence, Alan. Qualidade na educação da primeira infância: perspectivas pós-modernas. Tradução Magda França Lopes. Porto Alegre: Artmed, 2003.

Didonet, Vital. A educação infantil na educação básica e o FUNDEB. In: LiMA, Maria José Rocha; DidonEt, Vital (Org.). FUNDEB: avanços na universalização da educação básica. Brasília, DF: INEP, 2006.

Faria, Ana Lúcia G. de; Palhares, Marina. Educação infantil pós-LDB: rumos e desafios. Campinas: Autores Associados; São Carlos: Ed. da UFSCAR; Florianópolis: Ed. da UFSC, 1999.

Fortunati, Aldo. A educação infantil como projeto da comunidade: a experiência de São Miniato. Porto Alegre: Artmed, 2009.

Gimeno Sacristán, J. O aluno como invenção. Porto Alegre: Artmed, 2005.

Guimarães, José L.; Pinto, J. Marcelino Rezende. A demanda pela educação infantil e os recursos disponíveis para seu financiamento. Em Aberto, Brasília: INEP, v. 18, n. 74, p. 12-105, 2001.

HAdDAD, Lenira. Política integrada de Educação Infantil. Revista do SINPEEM, São Paulo: SINPEEM, n. 1, p. 40-43, jan./fev./mar. 2003.

James, Alison. Agency. In: Qvortrup, Jens; Corsaro, William A.; Honig, Michael-Sebastian. The palgrave handbook of childhood studies. London: Palgrave, 2009.

James, Alison; Prout, Alan. Constructing and reconstructing childhood. Contemporary issues in the Sociological Study of Childhood. 2. ed. London: RoutledgeFalmer, 1997.

James, Alison; Jenks, Chris; Prout, Alan. Theorizing childhood. Cambridge: Polity Press, 2002.

Jobim e Souza, Solange. Ressignificando a psicologia do desenvolvimento: uma contribuição crítica à pesquisa da infância. In: Kramer, Sonia; LeITe, Maria I. (Org.). Infância: fios e desafios da pesquisa. Campinas: Papirus, 1996.

Kramer, Sonia. A politica do pré-escolar no Brasil: a arte do disfarce. 5. ed. São Paulo: Cortez, 1995.

Kuhlmann JR., Moyses. Infância e educação infantil: uma abordagem histórica. Porto Alegre: Mediação, 1998.

. Educando a infância brasileira. In: Lopes, Eliane Marta T.; FARIA Filho, Luciano M.; VeIGA, Cynthia G. (Org.). 500 anos de educação no Brasil. Belo Horizonte: Autêntica, 2000. 
MAYALL, Berry. Towards a sociology of childhood, thinking from children's lives. London: Open University Press, 2002.

Moss, Peter; Petrie, Pat. From children's services to children's spaces. Public Policy, Children and Childhood. London: Routledge, 2002.

NARODOWsKI, Mariano. Infancia y poder: la conformación de la pedagogía moderna. 2. ed. Buenos Aires: Aique, 1999.

Organization For Economic Cooperation And Development (OECD). Starting strong II. Paris: OECD, 2006. Disponível em: <http://browse.oecdbookshop.org/ oecd/pdfs/browseit/9106031E.PDF>. Acesso em: dez. 2008.

QVorTrup, Jens. Nine theses about "childhood as a social phenomenon". Eurosocial Report. Childhood as a Social Phenomenon: Lessons from an International Project, n. 47 , p. $11-18,1993$.

. Childhood in Europe: a new field of social research. In: Chisholm, Linne (Ed.). Growing up in Europe. Contemporary horizons in childhood and youth studies. Berlin/New York: De Gruyer, 1995.

. Sociology of childhood: conceptual liberation of children. In: Mouritsen, F.; Qvortrup, J. (Ed.). Childhood and children's culture. Odense: Odense University Press, 2002.

Rocha, Eloisa Acires C. A pesquisa em educação infantil no Brasil: trajetória recente e perspectivas de consolidação de uma pedagogia. 1999. Tese (Doutorado em Educação) - Centro de Ciências da Educação, Universidade Federal de Santa Catarina.

A pedagogia e a educação infantil. Revista Brasileira de Educação, Rio de Janeiro: ANPEd; Campinas: Autores Associados, n. 16, p. 27- 34, 2001.

Rosemberg, Fúlvia (Org.). Creche. São Paulo: Cortez/FCC, 1989.

. A LBA, o Projeto Casulo e a Doutrina de Segurança Nacional. In: Freitas, Marcos C. de (Org.). História social da infância no Brasil. São Paulo: Cortez; Bragança Paulista: USF-IFAN, 1997.

Sarmento, Manuel. O ofício de criança. In: Congresso Internacional Os Mundos Sociais E Culturais Da InfÂncia, II., 2000, Braga, Universidade do Minho. Actas... p. $125-145$.

Visibilidade social e estudo da infância. In: VAsconcelLos, Vera Maria R.; Sarmento, Manuel J. (Org.). Infância (in) visível. Araraquara: Junqueira \& Marin, 2007. 
SiRota, Règine. Emergência de uma sociologia da infância: evolução do objeto e do olhar. Cadernos de Pesquisa, São Paulo: Fundação Carlos Chagas; Campinas: Autores Associados, n. 112, p. 7-31, mar. 2001.

Tredici, Tompson C. Adoção pelos municípios do estado de São Paulo de contratações de "Sistemas Apostilados de Ensino" de empresas privadas para aplicação nas escolas públicas municipais. Trabalho apresentado à Secretaria Diretoria Geral do Tribunal de Contas do Estado de São Paulo. 2007. Disponível em: <http://www.tce.sp.gov.br/artigos/ ArtPublicTompsonGestaoDemocEscolaSistemaApostilado.pdf >. Acesso em: dez. 2008.

\section{SOBRE A AUTORA}

Maria Letícia Barros Pedroso Nascimento é doutora em educação pela Universidade de São Paulo (USP). Professora da mesma instituição. E-mail: letician@usp.br

Recebido em setembro de 2011 Aprovado em novembro de 2011 


\section{MARIA LETÍCIA BARROS PEDROSO NASCIMENTO}

As políticas públicas de educação infantil e a utilização de sistemas apostilados no cotidiano de creches e pré-escolas públicas

Nos últimos vinte anos, pesquisas nacionais e internacionais, sustentadas principalmente por novos estudos sociais sobre a infância, têm oferecido novas possibilidades de compreender as instituições de educação infantil. A presente pesquisa é o resultado de projeto desenvolvido com o apoio da Fundação de Amparo à Pesquisa do Estado de São Paulo (FAPESP), cujo objetivo era saber quais municípios do estado de São Paulo adotam apostilas desenvolvidas e comercializadas por Sistemas Privados de Ensino e por que utilizam esse material. A investigação foi realizada em duas etapas: 
a primeira, por meio de questionários enviados a todas as cidades para verificar quais delas adotam apostilas, e a segunda, através de entrevistas semiestruturadas com as autoridades responsáveis pela educação infantil nos municípios. A análise procurou compreender os dados no contexto das teorias sociológicas da infância e das políticas públicas de educação infantil.

Palavras-chave: educação infantil; políticas públicas; apostilas; sociologia da infância.

\section{Early childhood education public policies and the adoption of "booklets" on crèches and preschools}

During the last twenty years, national and international research carried out mainly under the framework of the new social studies of childhood have offered new opportunities to understand the Early Childhood Education (ECE) institutions. The present study is a research project funded by the State of São Paulo Research Foundation (FAPESP), which aims to verify which municipalities in the state of Sao Paulo are adopting "booklets", developed and commercialized by private publishing companies and why do they use this material. The research was organized in two stages: the first one has sent questionnaires to every city to verify which ones adopted the booklets, and the second one proposed semi-structured interviews with authorities responsible for ECE in these municipalities. The analysis aims to put these different findings in the context of sociological theories of childhood and to understand some ECE public policies.

Keywords: early childhood education; public policies; booklets; sociology of childhood.

\section{Las políticas públicas de educación de la infancia y los 'libros de texto' en las guarderías y jardines de infancia}

En los últimos veinte años, las investigaciones nacionales e internacionales, apoyadas sobre todo por los nuevos estudios sociales de la infancia, han ofrecido nuevas posibilidades para la comprensión de las instituciones de educación de la infancia. Esta investigación es el resultado de un proyecto desarrollado con el apoyo de la Fundación para el Apoyo a la Investigación de São Paulo (FAPESP), cuyo objetivo fue conocer cuáles son las ciudades en el estado de São Paulo que aprueban libros de texto desarrollados y comercializados por los sistemas de enseñanza privada y por que utilizan este material. La investigación se realizó en dos etapas: en primer lugar, a través de cuestionarios enviados a todas las ciudades para ver cuál de ellos adopta libros de texto, y la segunda, a través de entrevistas estructuradas con las autoridades responsables de la educación infantil en los municipios. El análisis buscó comprender los datos en el contexto de las teorías sociológicas de la infancia $y$ de las politicas públicas de educación.

Palabras clave: educación infantil; políticas públicas; libros de texto; sociología de la infancia. 